\title{
Reactions of Saccharomyces cerevisiae and Zygosaccharomyces bailii to Sulphite
}

\author{
By BRIDGET J. PILKINGTON AND ANTHONY H. ROSE* \\ Zymology Laboratory, School of Biological Sciences, Bath University, Bath, Avon BA2 7AY, UK
}

(Received 22 April 1988)

\begin{abstract}
Sulphite inhibited growth of all four yeasts studied, Zygosaccharomyces bailii NCYC 563 being most sensitive and Saccharomyces cerevisiae NCYC 431 the least. Vertical Woolf-Eadie plots were obtained for initial velocities of ${ }^{35} \mathrm{~S}$ accumulation by all four yeasts suspended in high concentrations of sulphite. Equilibrium levels of ${ }^{35} \mathrm{~S}$ accumulation were reached somewhat faster with strains of $S$. cerevisiae than with those of $Z$. bailii. With all four yeasts, the greater the extent of ${ }^{35} \mathrm{~S}$ accumulation, the larger was the decline in internal $\mathrm{pH}$ value. Growth of $S$. cerevisiae TC8 and $Z$. bailii NCYC 563, but to a lesser extent of $S$. cerevisiae NCYC 431 and $Z$. bailii NCYC 1427, was inhibited when mid exponential-phase cultures were supplemented with 1.0 or $2.0 \mathrm{~mm}$-sulphite, the decrease in growth being accompanied by a decline in ethanol production. Unless growth was completely inhibited, the sulphite-induced decline in growth was accompanied by production of acetaldehyde and additional glycerol.
\end{abstract}

\section{INTRODUCTION}

Sulphite has long been recognized as a powerful antimicrobial agent (Hammond \& Carr, 1976). The compound exists in solution in three forms, the proportions of which depend on $\mathrm{pH}$ value. At $\mathrm{pH}$ values below $1 \cdot 8$, sulphite exists predominantly as free $\mathrm{SO}_{2}$ and at $\mathrm{pH}$ values above 7.2 largely as $\mathrm{SO}_{3}^{2-}$; at intermediate $\mathrm{pH}$ values, it exists in various proportions as the bisulphite ion ( $\mathrm{HSO}_{3}^{-}$; King et al., 1981). The antimicrobial action of sulphite is greatest at low $\mathrm{pH}$ values (Wedzicha, 1984), which explains why the compound is particularly effective against yeasts which, in general, grow best at pH values in the range 3.0-5.0 (Rose, 1987). The greater antimicrobial action of sulphite against Saccharomyces cerevisiae and Saccharomycodes ludwigii at low $\mathrm{pH}$ values has been explained by the discovery that, of the three molecular forms in which sulphite exists in solution, only $\mathrm{SO}_{2}$ enters these organisms (Stratford \& Rose, 1986; Stratford $e t$ al., 1987). Yeast species differ considerably in their ability to resist the antimicrobial action of sulphite. Warth (1985) found that Kloeckera apiculata and Hansenula anomala were much more sensitive to sulphite than strains of $S$. cerevisiae which is generally recognized as being a sulphiteresistant yeast. A yeast which has been reported to be even more resistant to sulphite is Zygosaccharomyces bailii (Thomas \& Davenport, 1985; Warth, 1985).

Little is known of the physiological basis for the different degrees of sulphite resistance among yeast species. Among strains of $S$. cerevisiae, differences in resistance have been attributed to production of compounds, particularly acetaldehyde, that bind sulphite to form $\alpha$-hydroxysulphonates (Burroughs \& Sparks, 1964), especially when the strains are grown in the presence of sulphite (Rankine, 1968; Rankine \& Pocock, 1969; Weeks, 1969). Moreover, Stratford et al. (1987) attributed the greater sulphite resistance of a strain of $S^{\prime}$ codes ludwigii as compared with one of $S$. cerevisiae to its ability to produce greater amounts of acetaldehyde. The resistance of S'codes ludwigii was also caused in part, it was suggested (Stratford et al., 1987), by its decreased ability to accumulate sulphite. The present paper compares the physiological basis of sulphite resistance in two strains each of $S$. cerevisiae and $Z$. bailii. 


\section{METHODS}

Organisms. The yeasts used were $S$. cerevisiae NCYC 431, S. cerevisiae TC8 (Stratford \& Rose, 1985), Z. bailii NCYC 563 and $Z$. bailii NCYC 1427. They were maintained at $4^{\circ} \mathrm{C}$ on slopes of malt extract-yeast extractglucose-mycological peptone (MYGP) agar (Wickerham, 1951).

Experimental cultures. Organisms were grown aerobically in a medium containing $\left(1^{-1}\right)$ : glucose, $20 \mathrm{~g}$; $\left(\mathrm{NH}_{4}\right)_{2} \mathrm{SO}_{4}, 3.0 \mathrm{~g} ; \mathrm{KH}_{2} \mathrm{PO}_{4}, 3.0 \mathrm{~g}$; yeast extract (Lab M), $1.0 \mathrm{~g} ; \mathrm{MgSO}_{4} .7 \mathrm{H}_{2} \mathrm{O}, 30 \mathrm{mg}$; and $\mathrm{CaCl}_{2} .2 \mathrm{H}_{2} \mathrm{O}, 30 \mathrm{mg}$ (adjusted to $\mathrm{pH} 4.0$ with $\mathrm{HCl}$ ). This is the medium used by Stratford \& Rose (1986) and is referred to as Medium A. It is, however, poorly buffered, and in experiments in which the yeasts were grown in the presence of sulphite it was replaced by Medium B which differed from Medium A in that $\mathrm{KH}_{2} \mathrm{PO}_{4}$ was omitted and replaced by $13.4 \mathrm{~g}$ $\mathrm{K}_{2} \mathrm{HPO}_{4}$ and $12.9 \mathrm{~g}$ citric acid. Under the conditions used, the $\mathrm{pH}$ value of cultures grown using Medium $\mathrm{B}$ did not fall below 4.0. Portions of medium (1 l ) were dispensed into 21 round flat-bottomed flasks which were plugged with cotton wool and sterilized by autoclaving at $6.89 \times 10^{4} \mathrm{~Pa}$ for $10 \mathrm{~min}$. Starter cultures $(100 \mathrm{ml}$ Medium A or B in $250 \mathrm{ml}$ conical flasks) were inoculated with a pinhead of yeast from a slant culture and incubated at $30{ }^{\circ} \mathrm{C}$ for $24 \mathrm{~h}$ on an orbital shaker ( 200 r.p.m.). Portions of medium (11) were inoculated with portions of starter culture containing $0.05 \mathrm{mg}$ dry wt $S$. cerevisiae NCYC $431,0.5 \mathrm{mg}$ dry wt $S$. cerevisiae TC8 or $1.0 \mathrm{mg}$ dry wt of either of the $Z$. bailii strains. Growth was followed by measuring the optical density of portions of culture, measurements being related to dry wt of organism by a standard curve constructed for each strain of yeast. Organisms were harvested from mid exponential-phase cultures, containing $0.5 \mathrm{mg}$ dry wt $S$. cerevisiae $\mathrm{ml}^{-1}$ or $0.25 \mathrm{mg}$ dry wt $Z$. bailii $\mathrm{ml}^{-1}$, by filtration through a membrane filter $(0.45 \mu \mathrm{m}$ pore size; $50 \mathrm{~mm}$ diam.; Oxoid) and washed twice with $10 \mathrm{ml} 30 \mathrm{~mm}$-citrate buffer ( $\mathrm{pH} \mathrm{3 \cdot 0)}$.

Assessment of sulphur dioxide tolerance. The ability of the yeasts to grow in Medium B containing different concentrations of sulphite was measured using Dynatech Microplates. Organisms were harvested from mid exponential-phase cultures by centrifugation $(12000 \mathrm{~g}$ for $2 \mathrm{~min}$ ) and resuspended in fresh medium $(\mathrm{pH} 4 \cdot 0)$ to give a suspension containing $0.1 \mathrm{mg} \mathrm{dry} \mathrm{wt} \mathrm{ml}^{-1}$. Cell suspension $(170 \mu 1)$ was pipetted into each well of a microtitre plate leaving one well empty to use as a blank. Sodium metabisulphite $(30 \mu \mathrm{l})$ diluted in fresh medium was added to each well giving final concentrations of sulphite ranging between zero and $3 \cdot 3 \mathrm{~mm}$ across the plate. The blank well was filled with $200 \mu \mathrm{l}$ water and the plate gently shaken for a few seconds to mix the suspensions. Replicate plates were prepared, covered, sealed in an airtight container with some moist tissue paper to minimize evaporation and incubated at $30^{\circ} \mathrm{C}$ on an orbital shaker $(200$ r.p.m.). Using a Dynatech Microplate Reader (MR600), set at $600 \mathrm{~nm}$, optical densities were measured at intervals up to $6 \mathrm{~h}$ after adjusting to zero against the blank well. Cells tended to settle to the bottom of the wells so the plates were gently agitated before optical densities were measured.

Measurement of sulphite accumulation. To measure initial velocities of sulphite accumulation, organisms grown in Medium A were washed twice with 30 mM-citrate buffer ( $\mathrm{pH} \mathrm{3.0)}$ containing $100 \mathrm{mM}$-glucose, suspended in the same buffer at $10 \mathrm{mg}$ dry wt ml-1 and the suspension allowed to equilibrate for $3 \mathrm{~min}$ at $30^{\circ} \mathrm{C}$. A reaction mixture consisting of $30 \mathrm{mM}$-citrate buffer ( $\mathrm{pH} \mathrm{3.0)}$ containing $100 \mathrm{mM}$-glucose and $10-200 \mu \mathrm{M}--^{35}$ S $]$ sulphite $\left(0.20 \mu \mathrm{Ci} \mathrm{ml}^{-1} ; 1 \mu \mathrm{Ci}=37 \mathrm{kBq}\right)$ was prepared in a universal bottle and warmed to $30^{\circ} \mathrm{C}$ in a water-bath. Labelled sulphite was stored at $-20^{\circ} \mathrm{C}$ in $5 \mathrm{mM}$-EDTA under nitrogen gas in $0.5 \mathrm{ml}$ portions $\left(0.1 \mathrm{mCi} \mathrm{ml}^{-1}\right)$ to prevent oxidation. Portions $(300 \mu \mathrm{l})$ of the suspension of organisms were dispensed into microcentrifuge tubes (Eppendorf). Using a $1.5 \mathrm{ml}$ multi-dispense syringe pipette, $1.25 \mathrm{ml}$ of labelled sulphite reaction mixture was added to the organisms and the suspension quickly mixed by refilling and emptying the syringe. After exactly $4 \mathrm{~s}$, $1.5 \mathrm{ml}$ of the suspension was rapidly filtered through a membrane filter $(0.45 \mu \mathrm{m}$ pore size; $25 \mathrm{~mm}$ diam.; Millipore) which had been washed with $5 \mathrm{ml} 10 \mathrm{mM}$-sulphite in $30 \mathrm{~mm}$-citrate buffer (pH 3.0). After filtration, three $1 \mathrm{ml}$ portions of buffered sulphite solution of the same concentration as used in the experiment were used quickly to wash the organisms and filter. Filters with organisms were then placed in scintillation vials containing $7 \mathrm{ml}$ Optiphase Safe (Fisons). Radioactivity in the vials was measured in an LKB Rackbeta liquid scintillation spectrometer (model 1217).

To measure the extent of sulphite accumulation, washed organisms grown in Medium A were suspended in glucose-containing citrate buffer as already described. Labelled sulphite was added to a suspension containing $2 \mathrm{mg}$ dry wt ml ${ }^{-1}$ giving a final concentration of $0.1-5.0 \mathrm{mM}$-sulphite $\left(0.2 \mu \mathrm{Ci} \mathrm{ml}^{-1}\right)$ and the suspension incubated at $30^{\circ} \mathrm{C}$. At appropriate time intervals, three $1 \mathrm{ml}$ portions of suspension were filtered through prewashed filters as already described. The organisms were washed with three $1 \mathrm{ml}$ portions of $30 \mathrm{~mm}$-citrate buffer containing sulphite at the concentration used in the experiment. Radioactivity was measured as already described. Background activity was estimated by repeating the procedure without organisms to check washing efficiency and to make sure that sulphite was not binding to filters.

Measurement of plasma-membrane area of organisms. Dimensions of organisms were measured by observation in a light microscope fitted with an eyepiece graticule. In calculating membrane areas, it was assumed that organisms of $S$. cerevisiae were spheres and those of $Z$. bailii cylinders with rounded ends.

Measurement of intracellular water volume. Volumes of intracellular water in organisms in suspension were 
calculated by measuring the differential distribution of ${ }^{3} \mathrm{H}_{2} \mathrm{O}$, which equilibrates with both extracellular and intracellular water, and $\mathrm{D}-\left[1-^{-14} \mathrm{C}\right]$ mannitol which is excluded by the plasma membrane. Preliminary experiments established that mannitol was not accumulated by any of the yeasts examined. To do this, washed organisms were suspended at $10 \mathrm{mg}^{2}$ ry wt ml-1 in $30 \mathrm{mM}$-citrate buffer (pH 3.0) containing $100 \mathrm{mM}$-glucose and $\left.{ }^{14} \mathrm{C}\right] \mathrm{mannitol}$ at $0.01,1.0$ or $100 \mathrm{mM}$. The suspensions were incubated for $60 \mathrm{~min}$ at $30^{\circ} \mathrm{C}$ and filtered through washed membrane filters $(0.45 \mu \mathrm{m}$ pore size; $50 \mathrm{~mm}$ diam.; Oxoid). The membranes were then washed with non-radioactive mannitol at the concentration used in the experiment, placed in scintillation vials containing $7 \mathrm{ml}$ Optiphase Safe and radioactivity was measured as already described. To measure the volume of intracellular water, a suspension of washed organisms (10 mg dry wt $\mathrm{ml}^{-1}$ ) grown in Medium A was prepared as already described. To $15 \mathrm{ml}$ of suspension was added $10 \mathrm{mM}-\left[{ }^{14} \mathrm{C}\right]$ mannitol $\left(0.02 \mu \mathrm{Ci} \mathrm{ml}^{-1}\right)$ and $0.2 \mu \mathrm{Ci}^{3} \mathrm{H}_{2} \mathrm{O} \mathrm{ml}^{-1}$. Suspensions were incubated with continuous stirring at $4^{\circ} \mathrm{C}$ for $10 \mathrm{~min}$. Six $1 \mathrm{ml}$ portions of suspension were then centrifuged in microcentrifuge tubes (Eppendorf) for $3 \mathrm{~min}$ at $12000 \mathrm{~g}$. Duplicate $200 \mu \mathrm{l}$ portions of supernatant from each tube were added to scintillation vials containing $7 \mathrm{ml}$ Optiphase Safe and radioactivity was measured as previously described. Radioactivity in the suspension of organisms was measured by placing $12200 \mu$ portions of suspension in scintillation vials containing $7 \mathrm{ml}$ Optiphase Safe.

Measurements of intracellular $\mathrm{pH}$ values. Intracellular $\mathrm{pH}$ values of organisms grown in Medium A were calculated by determining the equilibrium distribution of propionic acid across the plasma membrane (Conway \& Downey, 1950). Washed organisms, suspended $\left(5 \mathrm{mg} \mathrm{dry} \mathrm{wt} \mathrm{ml}^{-1}\right)$ in $30 \mathrm{~mm}$-citrate buffer $(9 \mathrm{ml})$ containing $100 \mathrm{~mm}$-glucose, were allowed to equilibrate after adding $1 \mathrm{ml} 0 \cdot 1 \mathrm{~mm}-\left[2-{ }^{14} \mathrm{C}\right]$ propionic acid $\left(0 \cdot 25 \mu \mathrm{Ci} \mathrm{ml}{ }^{-1}\right)$ at $30^{\circ} \mathrm{C}$. After $1,2,4,6,8$ and $10 \mathrm{~min}$, duplicate $300 \mu \mathrm{l}$ portions were taken from the suspension, rapidly filtered through washed membrane filters $(0.45 \mu \mathrm{m}$ pore size; $25 \mathrm{~mm}$ diam.; Millipore) and washed with $4 \times 1 \mathrm{ml}$ $0.01 \mathrm{~mm}$-propionic acid at $4{ }^{\circ} \mathrm{C}$. The filters with organisms were transferred to scintillation vials as already described. Once the time for equilibration had been ascertained, replicate measurements were obtained by sampling after $5 \mathrm{~min}$ incubation. Intracellular $\mathrm{pH}$ values were calculated from the expression derived by Waddell \& Butler (1959):

$$
\mathrm{pH}_{\mathrm{i}}=\mathrm{p} K_{\mathrm{i}}+\log _{10}\left[R\left(10^{\left(\mathrm{pH}_{\mathrm{e}}-\mathrm{p} K_{\mathrm{e}}\right)}+1\right)-1\right]
$$

where $R=T A_{\mathrm{i}} \cdot V_{\mathrm{e}} / T A_{\mathrm{e}} \cdot V_{\mathrm{i}}, \mathrm{pH}_{\mathrm{i}}$ and $\mathrm{pH}_{\mathrm{e}}$ are the internal and external $\mathrm{pH}$ values, $T A_{\mathrm{i}}$ and $T A_{\mathrm{e}}$ the intracellular and extracellular total amounts of propionic acid, $V_{\mathrm{i}}$ and $V_{\mathrm{e}}$ the intracellular and extracellular volumes and $\mathrm{p} K_{\mathrm{i}}$ and $\mathrm{p} K_{\mathrm{e}}$ the dissociation constants for propionic acid in the internal and external environments. The internal and external dissociation constants for propionic acid were calculated from the Davies (1962) simplified version of the DebyeHückel equations. Values for $\mathrm{p} K_{\mathrm{i}}$ and $\mathrm{p} K_{\mathrm{e}}$ were calculated to be 4.75 and 4.86 , respectively.

Analytical methods. Free $\mathrm{SO}_{2}$ was assayed by the method of Burroughs \& Sparks (1964), which assumes that dissociation of bound $\mathrm{SO}_{2}$ is minimized by lowering the $\mathrm{pH}$ value to $1 \cdot 5$. Acetaldehyde, glycerol and pyruvate were determined by using assay kits (Boehringer). Ethanol was determined by GLC as described by Beavan et al. (1982).

Chemicals. All reagents used were AnalaR or of the highest grade available commercially. Amersham supplied radioactively labelled chemicals

\section{RESULTS}

\section{Effects of sulphite on growth}

Sulphite inhibited growth of all four yeasts at concentrations up to and including $3.3 \mathrm{mM}$ as assessed by the microplate method (Fig. 1). Z. bailii NCYC 563 was the most sensitive and $S$. cerevisiae NCYC 431 the least.

\section{Accumulation of sulphite}

Vertical Woolf-Eadie plots (Hofstee, 1959) were obtained with initial velocities of accumulation by all yeasts suspended in high concentrations of $\mathrm{SO}_{2}$ (Fig. 2). However, at low concentrations of $\mathrm{SO}_{2}$ and especially with $S$. cerevisiae NCYC 431, there was considerable deviation from the vertical. Equilibrium levels for accumulation of sulphite equivalents were reached somewhat faster with the strains of $S$. cerevisiae than with those of $Z$. bailii although all four strains had reached these levels after $10 \mathrm{~min}$ irrespective of the concentration of sulphite. As suspensions of organisms accumulated equilibrium levels of sulphite equivalents measured after $10 \mathrm{~min}$ incubation, intracellular $\mathrm{pH}$ values declined (Fig. 3). The greater the extent of accumulation of sulphite equivalents, the larger was the decline in internal $\mathrm{pH}$ value. Equilibrium accumulation values, and therefore decline in internal $\mathrm{pH}$ values, were smallest for Z. bailii NCYC 1427 (Fig. 3). 


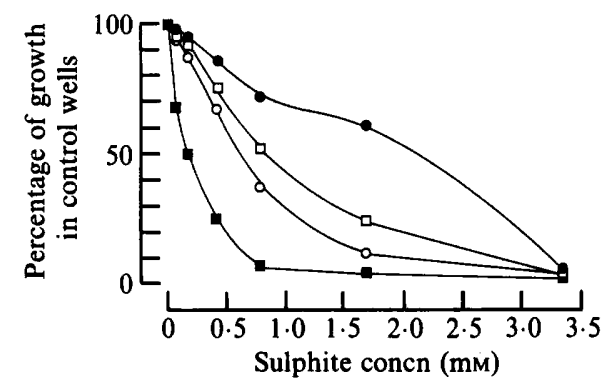

Fig. 1

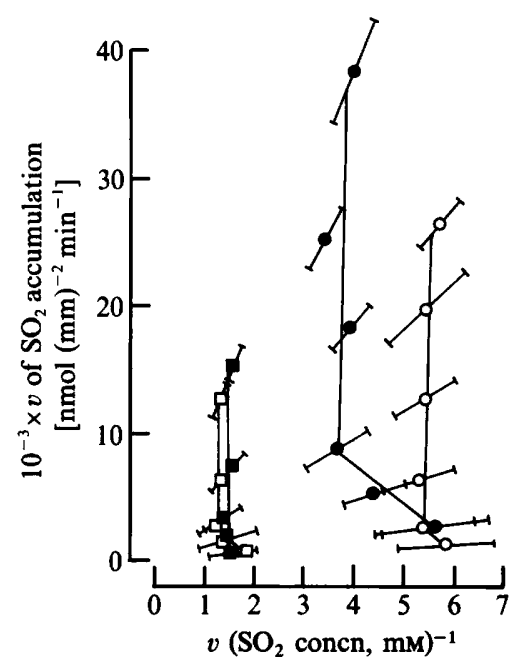

Fig. 2

Fig. 1. Effect of sulphite concentration on growth of $S$. cerevisiae TC8 (O), S. cerevisiae NCYC 431 (O), Z. bailii NCYC 1427 (口) and Z. bailii NCYC $563(\square)$ in Medium B in microtitre wells. Values quoted are the means of measurements on eight separate plates. The maximum variation was $\pm 10 \%$.

Fig. 2. Woolf-Eadie plots for accumulation of molecular $\mathrm{SO}_{2}$ by $S$. cerevisiae $\mathrm{TC} 8(\mathrm{O})$, $S$. cerevisiae NCYC $431(O), Z$. bailii NCYC $1427(\square)$ and Z. bailii NCYC $563(\square)$ suspended in 30 mM-citrate buffer (pH 3.0) containing $100 \mathrm{~mm}$-glucose at $30^{\circ} \mathrm{C}$. Concentrations of molecular $\mathrm{SO}_{2}$ were calculated from the data of King et al. (1981). Bars indicate SD.

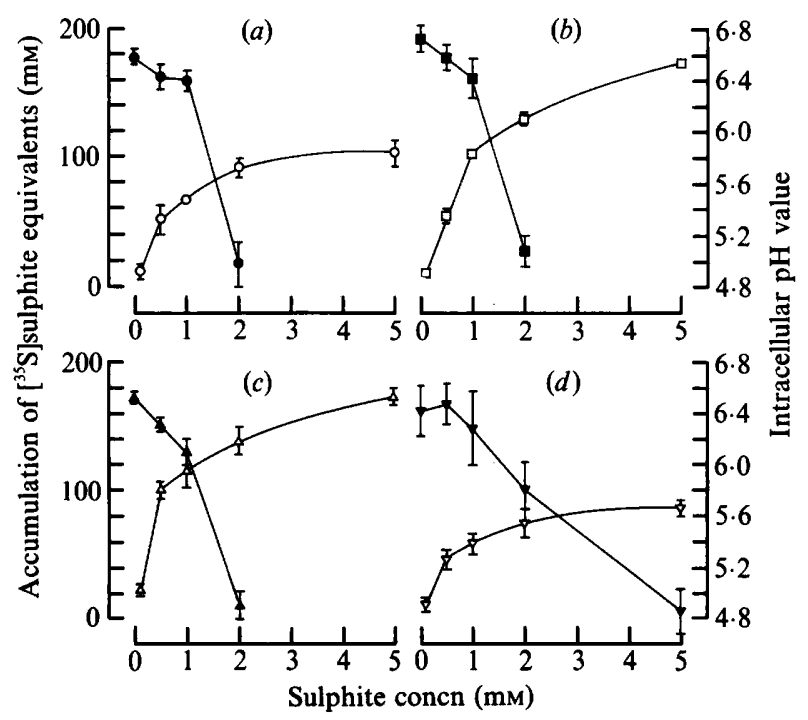

Fig. 3. Relationship between extent of accumulation of sulphite equivalents (open symbols) and intracellular pH values (closed symbols) in S. cerevisiae TC8 $(a), S$. cerevisiae NCYC $431(b), Z$. bailii NCYC $563(c)$ and $Z$. bailii NCYC $1427(d)$. Measurements were made after organisms had been suspended in buffer for $10 \mathrm{~min}$. Values quoted are means of at least three determinations. Bars indicate SD. 


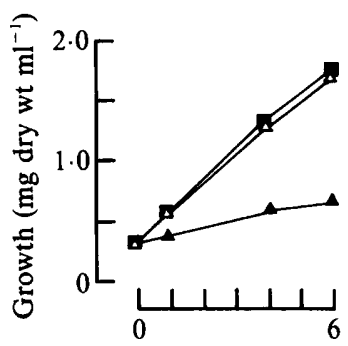

(a)

Incubation time (h)
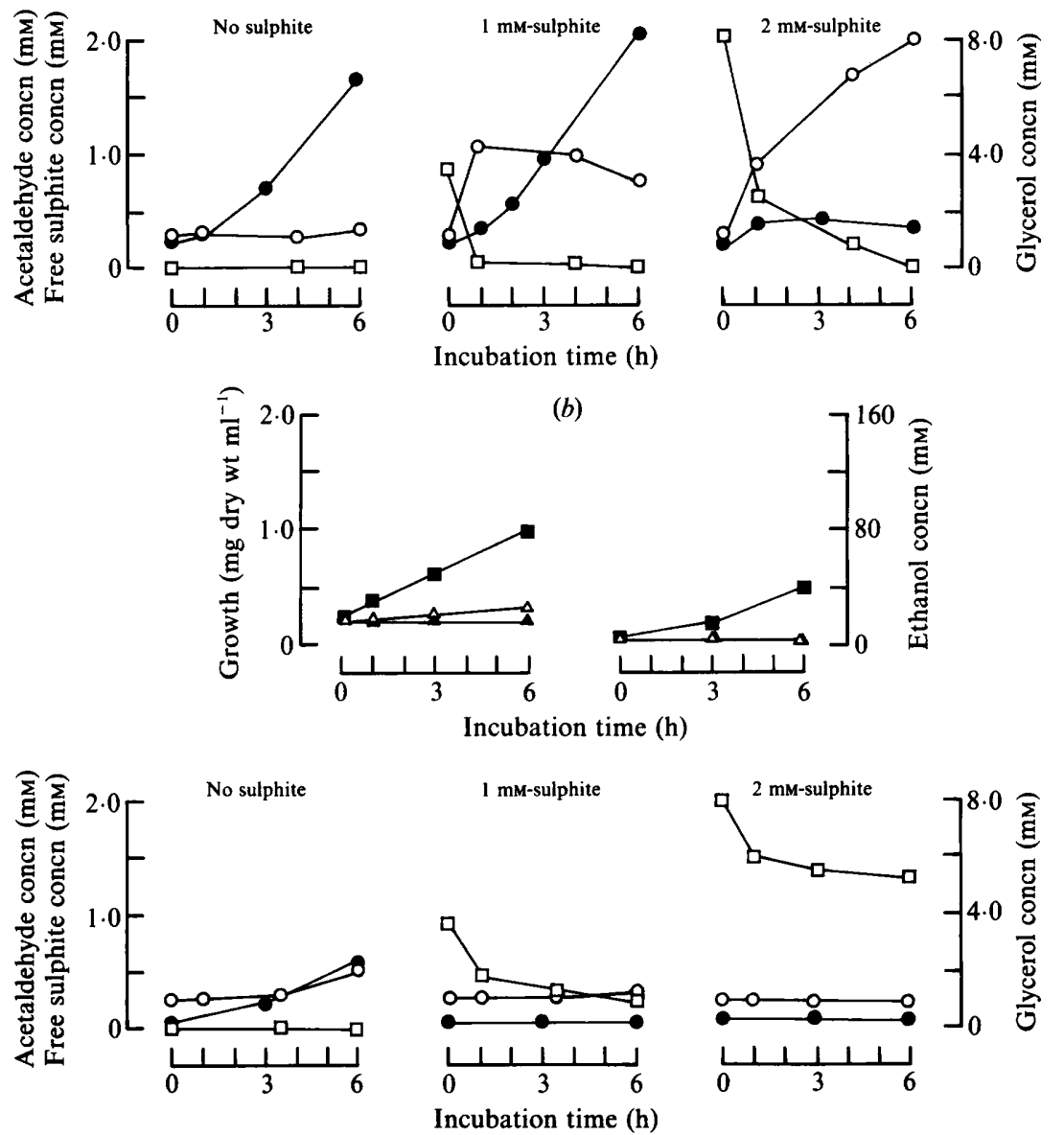

Fig. 4. Effect of supplementing cultures of $S$. cerevisiae NCYC 431 (a) and Z. bailii NCYC 563 (b) with sulphite $(\square$, control, $\triangle, 1.0 \mathrm{mM}, \triangle, 2 \mathrm{mM})$ on growth and ethanol formation. Also shown are the effects of these supplementations on concentrations of acetaldehyde $(O)$, glycerol $(O)$ and free sulphite $(\square)$ in culture supernatants. After supplementing cultures with sulphite, they were observed for a further $6 \mathrm{~h}$. Values quoted are the means of three separate determinations. The maximum variation in values for concentrations of acetaldehyde and free sulphite was $<10 \%$; for concentrations of ethanol and glycerol the variation was $\pm 15 \%$.

\section{Production of binding compounds by organisms grown in the presence of sulphite}

The effect of sulphite on growth of each of the yeasts in 1 litre cultures (Medium B) was assessed by adding the compound to mid exponential-phase cultures, and measuring the effect on density of organisms and on concentrations in culture filtrates of acetaldehyde, ethanol, glycerol, pyruvate and free sulphite over the following $6 \mathrm{~h}$. Growth of Z. bailii NCYC 563 was 
virtually completely inhibited following supplementation of cultures with 1.0 or $2.0 \mathrm{~mm}$-sulphite (Fig. $4 b$ ). Ethanol production was also completely inhibited. Even in the supplemented cultures in which growth was almost completely inhibited, there was a decrease in the concentration of free sulphite despite the lack of production of acetaldehyde. Production of glycerol and of pyruvate (not shown), which was detectable in unsupplemented cultures, was also completely inhibited. A very similar pattern of responses was observed in cultures of $S$. cerevisiae TC8 (data not shown). The much greater production of glycerol by this strain in unsupplemented cultures, which reached a concentration of approximately $7 \mathrm{mM}$ in $6 \mathrm{~h}$ cultures, was also completely inhibited by supplementation with 1.0 or $2.0 \mathrm{~mm}$-sulphite. Supplementing cultures of $S$. cerevisiae NCYC 431 with $1.0 \mathrm{~mm}$-sulphite had no effect on growth or ethanol production (Fig. $4 a$ ). In these cultures, the concentration of free sulphite declined rapidly, while there was an increased production of glycerol and rapid appearance of acetaldehyde in culture filtrates. When cultures of this yeast were supplemented with $2.0 \mathrm{~mm}$-sulphite, growth was decreased considerably and this was accompanied by decreased production of ethanol and glycerol (Fig. $4 a$ ). However, there was again a rapid decline in the concentration of free sulphite, which was accompanied by a greater increase in acetaldehyde concentration than was observed in cultures supplemented with 1.0 mM-sulphite. Again, production of pyruvate was unaffected (not shown). Cultures of $Z$. bailii NCYC 1427 showed a very similar pattern of responses to those of $S$. cerevisiae NCYC 431 (data not shown), except that less glycerol was produced in unsupplemented cultures while supplementation with $1.0 \mathrm{~mm}$-sulphite lowered glycerol production.

\section{DISCUSSION}

The two strains of $S$. cerevisiae used to compare sulphite resistance with strains of $Z$. bailii, which have been reported to be extremely resistant to the compound (Thomas \& Davenport, 1985; Warth, 1985), were selected without any knowledge of their reaction to sulphite. $S$. cerevisiae NCYC 431 is a strain originating from a distillery, and has a high tolerance of ethanol (Cartwright et al., 1986, 1987), while S. cerevisiae TC8 is a strain used in cider-making and which has been reported to excrete $\mathrm{H}_{2} \mathrm{~S}$ (Stratford \& Rose, 1985). It was surprising, therefore, to find that, of the four strains examined, one of $S$. cerevisiae was the most tolerant to sulphite while a strain of $Z$. bailii was the most sensitive. The availability of authenticated strains of $Z$. bailii is limited. $Z$. bailii NCYC 563 was included in the survey because it has been used in research into sulphite resistance of spoilage yeasts (Cole et al., 1987). Significantly, it was the least resistant of the strains examined in the present study.

Two yeasts, namely S. cerevisiae (Stratford \& Rose, 1986) and S'codes ludwigii (Stratford et al., 1987), have been shown to transport $\mathrm{SO}_{2}$ by free diffusion, based on evidence from vertical Woolf-Eadie plots. The present report shows that passage of $\mathrm{SO}_{2}$ into strains of $Z$. bailii is also by free diffusion. It was also interesting to note that the deviation from verticality, observed in the present study with strains of $Z$. bailii and previously with $S$. cerevisiae TC8 (Stratford \& Rose, 1986) and $S^{\prime}$ codes ludwigii (Stratford et al., 1987), was very much more pronounced with $S$. cerevisiae NCYC 431. This suggests that, at low concentrations of $\mathrm{SO}_{2}$, a facilitated transport system operates, possibly to transport the $\mathrm{HSO}_{3}^{-}$ion. With vertical Woolf-Eadie plots, the value at the intercept on the abscissa is equivalent to the permeability coefficient for passage of $\mathrm{SO}_{2}$ into the organism (Laidler, 1977). It is clear, therefore, that the two strains of $Z$. bailii have lower permeability coefficients than either of the $S$. cerevisiae strains.

Our discovery of a correlation between ability of yeasts to grow in the presence of sulphite and sulphite-induced production of acetaldehyde suggests that production of this sulphite-binding compound contributes significantly to the resistance. It is also noteworthy that the two most sulphite-resistant yeasts examined, namely $S$. cerevisiae NCYC 431 and $Z$. bailii NCYC 1427, are able to produce large amounts of acetaldehyde when growth was almost completely inhibited by $2.0 \mathrm{~mm}$-sulphite. Excretion of acetaldehyde together with glycerol in cultures of $S$. cerevisiae supplemented with sulphite has been known for many years (Neuberg \& Reinfurth, 1918, 1919), and constitutes Neuberg's second form of fermentation (Nord \& Weiss, 1958). Our data are in general agreement with the finding of Neuberg \& Reinfurth (1919) that, in the presence of 
sulphite, acetaldehyde and glycerol are produced in equimolar amounts by strains of $S$. cerevisiae. Moreover, the data show for the first time that this is true also for strains of $Z$. bailii. Production of glycerol by $Z$. acidifaciens (now recognized as $Z$. bailii) was reported by Nickerson \& Carroll (1945).

When $\mathrm{SO}_{2}$ enters the yeast cell, it encounters an environment which is around $\mathrm{pH} 6.5$ with the result that a large proportion of the $\mathrm{SO}_{2}$ is converted into $\mathrm{HSO}_{3}^{-}$. This explains the ability of yeasts to concentrate sulphite intracellularly. At the same time, the intracellular $\mathrm{pH}$ value declines, which in turn lowers the transmembrane $\mathrm{pH}$ gradient and hence dissipates the protonmotive force across the plasma membrane. A result of this would be to retard or inactivate processes, such as active transport of solutes, that require energy from the proton-motive force. The discovery that the decrease in internal $\mathrm{pH}$ value following accumulation of sulphite is not of the same magnitude in all strains of yeast suggests that the internal buffering capacity of organisms might be important in sulphite resistance. While invoking a role for energy metabolism in sulphite resistance of yeasts, it is worth noting that exposure of $S$. cerevisiae to sulphite leads to a rapid decrease in the content of ATP (Schimz \& Holzer, 1979) which has been attributed primarily to the action of sulphite on the enzyme glyceraldehyde-3-phosphate dehydrogenase (Hinze \& Holzer, 1986).

The research reported in this paper was generously supported by the AFRC. We also thank Jill Calderbank for advice.

\section{REFERENCES}

Beavan, M. J., Charpentier, C. \& Rose, A. H. (1982). Production and tolerance of ethanol in relation to phospholipid fatty-acyl composition in Saccharomyces cerevisiae NCYC 431. Journal of General Microbiology 128, 1447-1455.

Burroughs, L. F. \& Sparks, A. H. (1964). The identification of sulphur dioxide-binding compounds in apple juices and ciders. Journal of the Science of Food and Agriculture 15, 176-185.

Cartwright, C. P., Juroszek, J.-R., Beavan, M. J., Ruby, F. M. S., De Morais, S. M. F. \& Rose, A. H. (1986). Ethanol dissipates the proton-motive force across the plasma membrane of Saccharomyces cerevisiae. Journal of General Microbiology 132, 369377.

Cartwright, C. P., Veazey, F. J. \& Rose, A. H. (1987). Effect of ethanol on activity of the plasmamembrane ATPase in, and accumulation of glycine by, Saccharomyces cerevisiae. Journal of General Microbiology 133, 857-865.

Cole, M. B., Franklin, J. G. \& Keenan, M. H. J. (1987). Probability of growth of the spoilage yeast Zygosaccharomyces bailii in a model fruit drink system. Food Microbiology 4, 115-119.

CONWAY, E. J. \& DownEY, M. (1950). pH values of the yeast cell. Biochemical Journal 47, 355-360.

DAvies, C. W. (1962). Ion Association, pp. 39-43. London \& Boston: Butterworth.

HAMmOND, S. M. \& CARR, J. G. (1976). The antimicrobial activity of $\mathrm{SO}_{2}$ with particular reference to fermented and non-fermented fruit juices. In Inhibition and Inactivation of Vegetative Microbes, pp. 89110. Edited by F. A. Skinner \& W. B. Hugo. London: Academic Press.

Hinze, H. \& HolzER, H. (1986). Analysis of the energy metabolism after incubation of Saccharomyces cerevisiae with sulfite or nitrite. Archives of Microbiology 145, 27-31.
HoFsTEE, B. H. J. (1959). Non-inverted versus inverted plots in enzyme kinetics. Nature, London 184, 12961298.

King, A. D., JR, Ponting, J. D., Sanschuck, D. W., JACKSON, R. \& MiHARA, K. (1981). Factors affecting death of yeast by sulphur dioxide. Journal of Food Protection 44, 92-97.

LAIDLER, K. (1977). Physical Chemistry with Biological Applications. New York: Benjamin Cummings Publishing $\mathrm{Co}$.

NeUberG, C. \& ReINFURTH, E. (1918). Naturliche und erzwungene Glycerin-bildung bei der alkoholischen Gärung. Biochemische Zeitschrift 92, 234-266.

NeUberG, C. \& ReINFURTh, E. (1919). Weitere Untersuchungen über die korrelative Bildung von Acetaldehyd und Glycerin bei der Zuckersplatung und neue Beiträge zur theorie der alkoholischen Gärung. Berichte der Deutschen chemischen Gesellschaft 52, 1677-1703.

Nickerson, W. J. \& Carroll, W. R. (1945). On the metabolism of Zygosaccharomyces. Archives of Biochemistry 7, 257-271.

NORD, F. F. \& WEISS, S. (1958). Fermentation and respiration. In The Chemistry and Biology of Yeasts, pp. 323-368. Edited by A. H. Cook. New York: Academic Press.

RANKINE, B. C. (1968). Formation of $\alpha$-ketoglutaric acid by wine yeasts and its oenological significance. Journal of the Science of Food and Agriculture 19, 624627.

RANKINE, B. C. \& Pocock, K. F. (1969). Influence of yeast strain on binding of sulphur dioxide in wines and on its formation during fermentation. Journal of the Science of Food and Agriculture 20, 104-109.

Rose, A. H. (1987). Responses to the chemical environment. In The Yeasts, 2nd edn, vol. 2, pp. 540. Edited by A. H. Rose \& J. S. Harrison. London: Academic Press. 
SCHIMZ, K.-L. \& HolZER, H. (1979). Rapid decrease of ATP content in intact cells of Saccharomyces cerevisiae after incubation with low concentrations of sulfite. Archives of Microbiology 121, 225-229.

STRATFORD, M. \& Rose, A. H. (1985). Hydrogen sulphide production from sulphite by Saccharomyces cerevisiae. Journal of General Microbiology 131, 14171424.

StRATFORD, M. \& Rose, A. H. (1986). Transport of sulphur dioxide by Saccharomyces cerevisiae. Journal of General Microbiology 132, 1-6.

Stratford, M., Morgan, P. \& Rose, A. H. (1987). Sulphur dioxide resistance in Saccharomyces cerevisiae and Saccharomycodes ludwigii. Journal of General Microbiology 133, 2173-2179.

Thomas, D. S. \& DAVENPoRT, R. R. (1985). Zygosaccharomyces bailii - a profile of characteristics and spoilage activities. Food Microbiology 2, 157169.
WARTH, A. D. (1985). Resistance of yeast species to benzoic and sorbic acids and to sulfur dioxide. Journal of Food Protection 48, 564-569.

WADDELL, W. J. \& BUTLER, T. C. (1959). Calculation of intracellular $\mathrm{pH}$ from the distribution of 5,5dimethyl-2,4-oxazolidinedione (DMO). Application to skeletal muscle of the dog. Journal of Clinical Investigation 38, 720-729.

WEDZICHA, B. L. (1984). Chemistry of Sulphur Dioxide in Foods. London: Elsevier Applied Science Publishers.

WeEks, C. (1969). Production of sulphur dioxidebinding compounds and of sulphur dioxide by two Saccharomyces yeasts. American Journal of Enology and Viticulture 20, 32-39.

WiCKerHAM, L. J. (1951). Taxonomy of yeasts. I. Techniques of classification. United States Department of Agriculture Technical Bulletin no. 1029. Washington, DC: US Department of Agriculture. 